Original Research Paper

\title{
Identification of Venom-Specific Fingerprints of Clinically Relevant Uruguayan Snakes by MALDI-TOF
}

\author{
Norma Suarez and Victor Morais \\ Department of Biotechnology, Institute of Hygiene, Faculty of Medicine, \\ University of the Republic, Montevideo, Uruguay
}

\author{
Article history \\ Received: 24-04-2019 \\ Revised: 30-05-2019 \\ Accepted: 20-07-2019 \\ Corresponding Author: \\ Dr. Victor Morais \\ Department of Biotechnology, \\ Institute of Hygiene, Faculty of \\ Medicine, University of the \\ Republic, Montevideo, \\ Uruguay \\ Tel: +59824871288 ext 1044 . \\ Fax: +59824873073 \\ E-mail:vmorais@higiene.edu.uy
}

\begin{abstract}
Snakebite envenomation is a particular public health problem in many areas of the world, including extensive areas of Latin America. In particular, in Uruguay, snakebite accidents are caused by two snakes of the genus Bothrops: Bothrops alternatus and Bothrops pubescens. The only effective treatment available is the administration of the specific antivenom. Although there is an ELISA that allows the determination of venom in serum samples, the technique does not allow discrimination between the two species and can also generate uncertainty in the case of foreign snakes, highlighting the need for alternative analytical methods that ensure species identification. The aim of this work was to use of Matrix-Assisted Laser Desorption/Ionization Time-of-Flight Mass Spectrometry (MALDI-TOF MS) for the identification and discrimination of $B$. pubescens and B. alternatus venoms and evaluate the suitability for diagnostic use. The two venoms were compared by SDS-PAGE and MALDI-TOF MS. The results showed similar protein profiles for both venoms with differences in the distribution of bands by SDS-PAGE densitometry. However, the use of the MALDI-TOF MS technique allowed discrimination between these two venoms, providing characteristic "fingerprints" that are proposed as a new tool suitable for clinical diagnosis.
\end{abstract}

Keywords: Snake Venom, Densitometry, Matrix-Assisted Laser Desorption/Ionization Time-of-Flight Mass Spectrometry (MALDI-TOF MS)

\section{Introduction}

Snakebite envenomation is a neglected tropical disease and a particular public health problem in many areas of the world, including extensive areas of Latin America (Theakston et al., 2003; WHO, 2010). Recently the World Health Organization (WHO) estimate in about 2.7 million cases of envenoming and 81 000-138 000 deaths every year (WHO, 2019).

In Uruguay, an average of 65 snakebite accidents are reported each year (Morais et al., 2006; Morais et al., 2012). All are caused by snakes in the genus Bothrops: B. Pubescens (BP) and B. Alternatus (BA). Accidents generally occur during the warm months of the year, coinciding with the period of greater biological and metabolic activity of the snake. Snakebite accidents are almost exclusive to suburban and rural areas, occurring predominantly in rural workers. The toxic effect of Bothrops venom is mainly characterized by alterations in coagulation and important local damage that can lead to amputation of the affected limb in severe cases (Markland, 1998; Matsui et al., 2000). These toxic effects are caused by several protein families including metaloproteases, serinoproteases, phospholipases A2, among others (Calvete et al., 2007; Calvete, 2011a; Gay et al., 2015). The envenomation diagnosis is based on clinical evidence and coagulation parameter analysis, but it is not possible to distinguish between the two species.

Antivenom constitutes the only effective treatment for snake bite envenomation (Chippaux and Goyffon 1998; Theakston et al., 2003). Antivenoms are constituted by antibodies purified from immunized animals against snake venom. Every snake specie have a particular profile of toxins showing immunological differences and thus the antivenom is specific against the snake specie (WHO, 2010).

Numerous countries have many snake species that can cause severe envenoming so it is important to discriminate the specie to know what type of antivenom should be used (WHO, 2019). The snake antivenom used in Uruguay is bivalent (neutralize the venom of the two species), so the discrimination of the two types of venom 
is not important for patient treatment, but it could be useful for the determination of the physiopathological differences that can exist between them.

Additionally, the entry of foreign specimens as pets for private collections has recently introduced a situation in the country that is not completely regulated and could generate an accident involving confusion between a foreign and a native snake; consequently, the antivenom treatment could be unsuccessful. For doubtful cases, an Enzyme-Linked Immunosorbent Assay (ELISA) is available and can detect venom antigenaemia with a very good sensitivity $(10 \mathrm{ng} / \mathrm{mL})$, but it is only effective for native venoms (Morais et al., 2012).

The use of heterologous proteins for human treatment might activate the immune system and cause adverse reactions, including mild symptoms such as chills, nausea and fever or more serious problems such as bronchospasm and anaphylactic shock and the rational use of antivenom is thus very important (Otero-Patiño et al., 1998; Morais and Massaldi, 2009; Morais, 2018)

Matrix-assisted laser desorption deionization time-offlight mass spectrometry (MALDI-TOF MS) technique is highly developed for the diagnosis of microorganisms, with important databases of profiles for the identification of pathogens (Pranada et al., 2015). The technique allows the generation of characteristic peptide and protein profiles that serve as a "fingerprint" for the identification of the species, which are becoming a very important tool in diagnostic material. The robustness of the technique has been demonstrated for a wide range of organism (Demirev and Fenselau, 2008; Qian et al., 2008; Fenselau, 2013).

Furthermore, the technique can quickly identify proteins present in unknown cellular suspensions or from complex mixtures (Liang et al., 1996; Pineda et al., 2000). The ability of this technique to rapidly and accurately discriminate for bacterial species has become a revolution in the clinical microbiology and has demonstrated the power of this tool (Demirev and Fenselau, 2008; Hrabák et al., 2013; Karimi and Amanati, 2016).

In the case of snake venoms, MALDI-TOF MS is commonly used to identify the composition of a particular snake venom or for identification of snake species in crude venom but not for diagnostic purpose in patients biological samples (Chapman et al., 2003; Calvete et al., 2007; Calvete, 2011b).

The aim of this work was to use of MALDI-TOF MS for the identification and discrimination of $B$. pubescens and B. alternatus venoms and evaluate the suitability for diagnostic use.

\section{Materials and Methods}

Venom of Bothops Pubescens (BP) and Bothrops Alternatus (BA) were obtained from the Serpentarium at the Institute of Hygiene, Uruguay. MALDI matrix 3, 5-
Dimethoxy-4-hydroxy-cinnamic acid (sinapinic acid) and peptide calibration standard mix were purchased from Bruker Daltonics (Billerica, MS, USA).

SE 260 mini vertical gel electrophoresis unit and Coomassie Brilliant Blue were purchased from Amersham Bioscience and Sigma, USA respectively.

\section{SDS-PAGE Analysis}

Sodium Dodecyl Sulphate Polyacrylamide Gel Electrophoresis (SDS-PAGE) was carried out according to the method of Laemmli (1970). Non-reducing samples of venom $(50 \mu \mathrm{g})$ or reduced samples (plus $0.1 \mathrm{M} \mathrm{DTT}$ ) were loaded onto a $12.5 \%$ acrylamide gel and run in an SE 260 mini vertical gel electrophoresis unit at $20 \mathrm{~mA}$ for $1 \frac{1}{2}$ hour. The gels were then stained with Coomassie Brilliant Blue.

\section{Densitometry Analysis}

Band quantification was performed using Gel-Pro Analyzer 3.1 software (Media Cybernetics). The densitometry analysis was performed on the resulting images by a desktop scanner and digital photographic machine. The band selection was performed manually, the same filter was applied to eliminate noise in all cases and the quantification was determined by the relative percentage of the band in relation to the amount loaded in the lane.

\section{MALDI-TOF Analysis}

MALDI measurements were conducted on a Microflex LR MALDI-TOF (Bruker Daltonics, Billerica, MS, USA) with a $337 \mathrm{~nm}$ nitrogen laser operated in positive ion linear mode with delayed extraction and optimized in the $\mathrm{m} / \mathrm{z}$ range of 0 to $20 \mathrm{kDa}$. Calibrations were performed with a peptide calibration standard mix (Bruker Daltonics). The laser was fired 100 times at each of ten locations for each sample well on a 96-well plate for a cumulative 1000 shots per sample well taken at $30 \%$ intensity.

At the time of analysis, $1 \mu \mathrm{L}$ of each of the samples was mixed with $1 \mu \mathrm{L}$ of matrix solution Sinapinic Acid (SA) $10 \mathrm{mg} / \mathrm{ml}$ in sterile water with $1 \%$ TFA or 2,5 Dihydroxybenzoic Acid (DHB) at a ratio of 1:1. The sample and matrix mix was spotted onto a 96-well stainless steel plate and allowed to air dry for $15 \mathrm{~min}$ at room temperature.

\section{Results}

All the venoms patterns were analyzed by SDS gel electrophoresis and by a mass spectrometry. The matrix selected for the identification of the venoms proteins were SA and DHB, these organic matrices demonstrated to provide an effective ionization of other organisms. The spectra patterns obtained were evaluated on the 
basis of signal strength, resolution and reproducibility. These criteria are all essential for effective fingerprinting (Krishnamurthy et al., 2000; Fenselau, 2013)

Figure 1 shows the protein profiles of both venoms obtained by SDS-PAGE electrophoresis. High similarity of the protein location bands of the two venoms was observed. However, the densitometry of the bands shows important differences in concentration (Table 1). The most important band of BA is located at $49-51 \mathrm{kDa}(62$ $\mathrm{kDa}$ under reducing conditions), corresponding to approximately $32 \%$ of the total venom. The counterpart of BP corresponds to only $6 \%$ of the total venom. On the other hand, the most important band of BP is located at $18-20 \mathrm{kDa}$, corresponding to $33 \%$ of the total venom, while in BA, it corresponds to $10 \%$.

Figures 2 and 3 show the mass profiles of both venoms with SA and DHB matrices, respectively. The highest sensitivity achieved with SA was $1 \mathrm{ng}$ (1000 $\mathrm{ng} / \mathrm{mL}$ ), whereas the use of DHB matrix allowed an increase in the sensitivity to $100 \mathrm{pg}(100 \mathrm{ng} / \mathrm{mL})$. The presence of plasma in the venom sample did not interfere with the peak visualization.

In the case of Bothrops alternatus with a concentration of $1 \mathrm{ng} / \mathrm{mL}$, the protein profile (Fig. 2) showed three outstanding peaks at approximately $\mathrm{m} / \mathrm{z}$ 2638, $\mathrm{m} / \mathrm{z} 3821, \mathrm{~m} / \mathrm{z} 7712$, whereas for Bothrops pubescens, the peaks were at approximately $\mathrm{m} / \mathrm{z} 8869$ and $\mathrm{m} / \mathrm{z} 13771$.

Table 1: The relative concentration of most abundant components of both venoms

\begin{tabular}{lll}
\hline Band $(\mathrm{MW})$ & $\begin{array}{l}\text { Bothrops } \\
\text { alternatus }\end{array}$ & $\begin{array}{l}\text { Bothrops } \\
\text { pubescens }\end{array}$ \\
\hline $49-51 \mathrm{KDa}$ & $32 \%$ & $6 \%$ \\
$26 \mathrm{KDa}$ & $12 \%$ & $2 \%$ \\
$23 \mathrm{KDa}$ & $9 \%$ & $20 \%$ \\
$18-20 \mathrm{KDa}$ & $9 \%$ & $33 \%$ \\
\hline
\end{tabular}

Figure 3 shows the protein profile of $100 \mathrm{ng} / \mathrm{mL}$ of Bothrops alternatus venom with three outstanding peaks at approximately $\mathrm{m} / \mathrm{z} 2274, \mathrm{~m} / \mathrm{z} 3543, \mathrm{~m} / \mathrm{z} 4884$ and of Bothrops pubescens with three outstanding peaks at approximately m/z4825, m/z 6830 and 13766 .

\section{Discussion}

Envenomation resulting from snakebites is an important public health problem, particularly in South and Central America. The distinct clinical manifestations and lethality in snakebite are the result of different types of venom, which are complex mixtures of biologically active components (WHO, 2019). In particular, the venoms of many snake species cause important alterations in the coagulation system and local tissue damage (WHO, 2019). The presence of these alterations is, in fact, the indication that the patients were envenomed by snake venom, increasing the need for access to antivenom treatment via the health system (Morais et al., 2012).

In Uruguay, envenomation by Bothrops snakes shows similar clinical manifestations, making it impossible to discriminate between the two species. Nevertheless, the identification of the species is irrelevant for clinical purposes due to the bivalent nature of the antivenom (Morais et al., 2012). Recently, however, many people in the country have acquired foreign snake species as pets. Although many of the snakes of the Viperidae family generate similar clinical manifestations, it becomes very relevant to identify the snake species in case of a possible accident involving a foreign snake because the clinical manifestations might be similar, but the antivenom cross neutralization could fail.

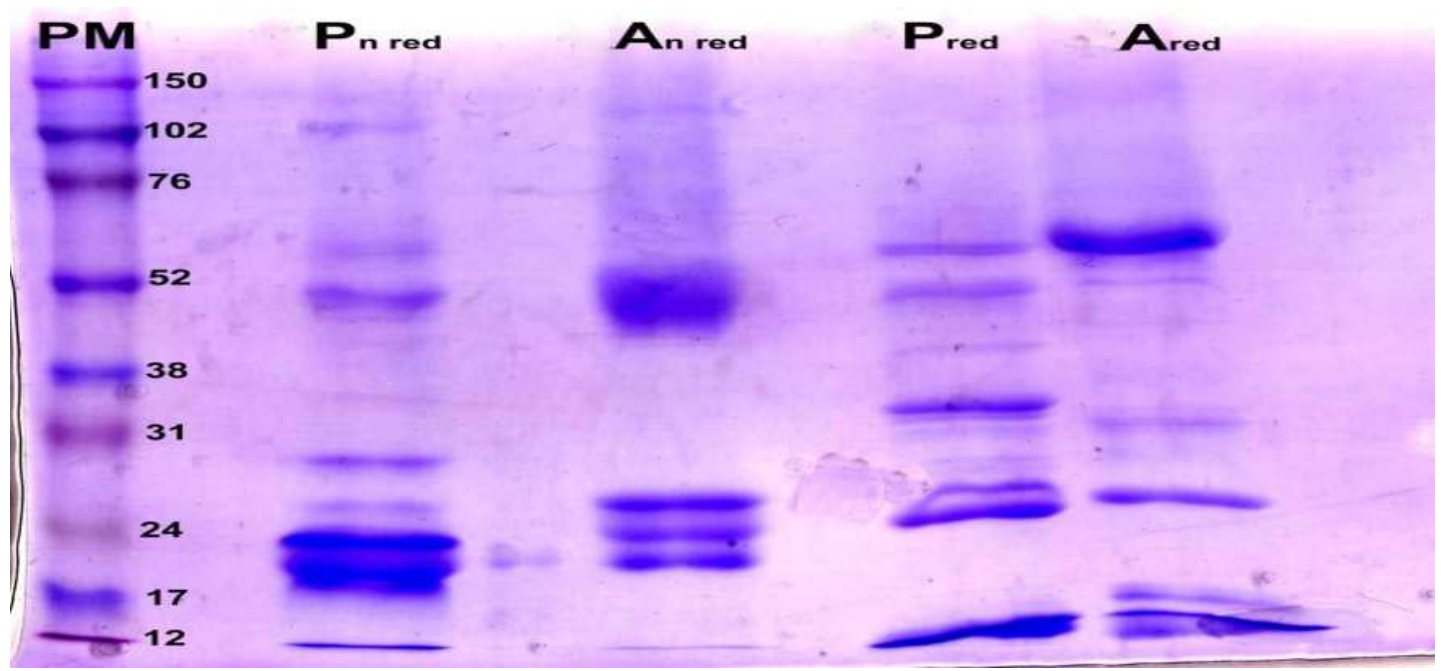

Fig. 1: Proteins profiles of B. alternatus (A) y B. pubescens (P) by SDS PAGE. Lane (1) MW; Lane (2) BP not reduced. Lane (3) BA not reduced. Lane 4 BP reduced. Lane 4) BA reduced 


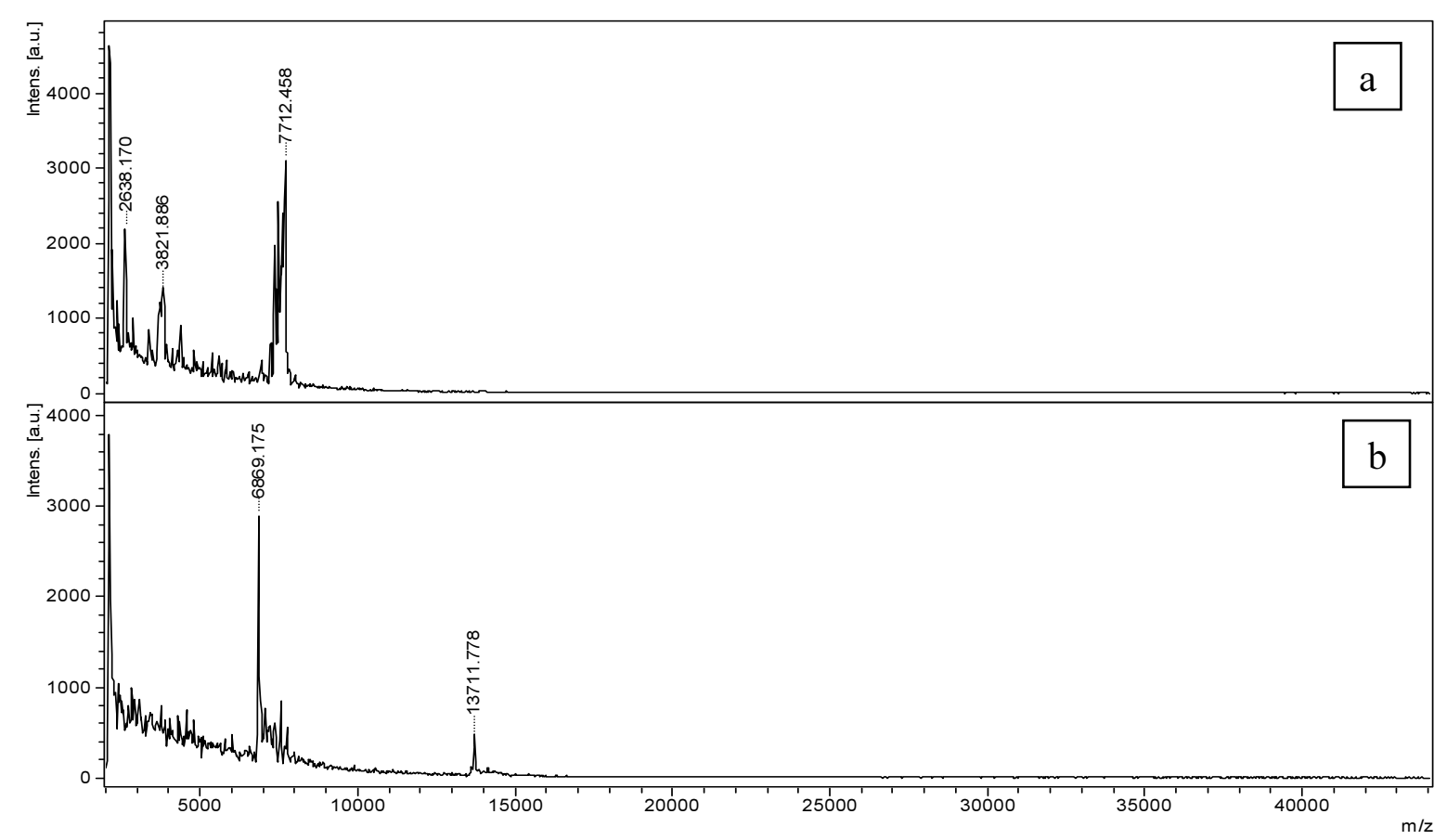

Fig. 2: Representative MALDI-TOF spectra of Bothrops alternatus and Bothrops pubescens Comparative MALDI-TOF mass pectra of 1

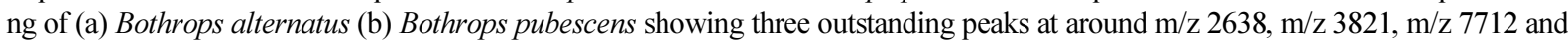
in Bothrops alternatus profile; and two outstanding peaks at around m/z 8869 and 3711 inBothropspubescensprofile. The products were detected as $[\mathrm{M}+\mathrm{Na}]+$ and/or $[\mathrm{M}+\mathrm{K}]+$ ions

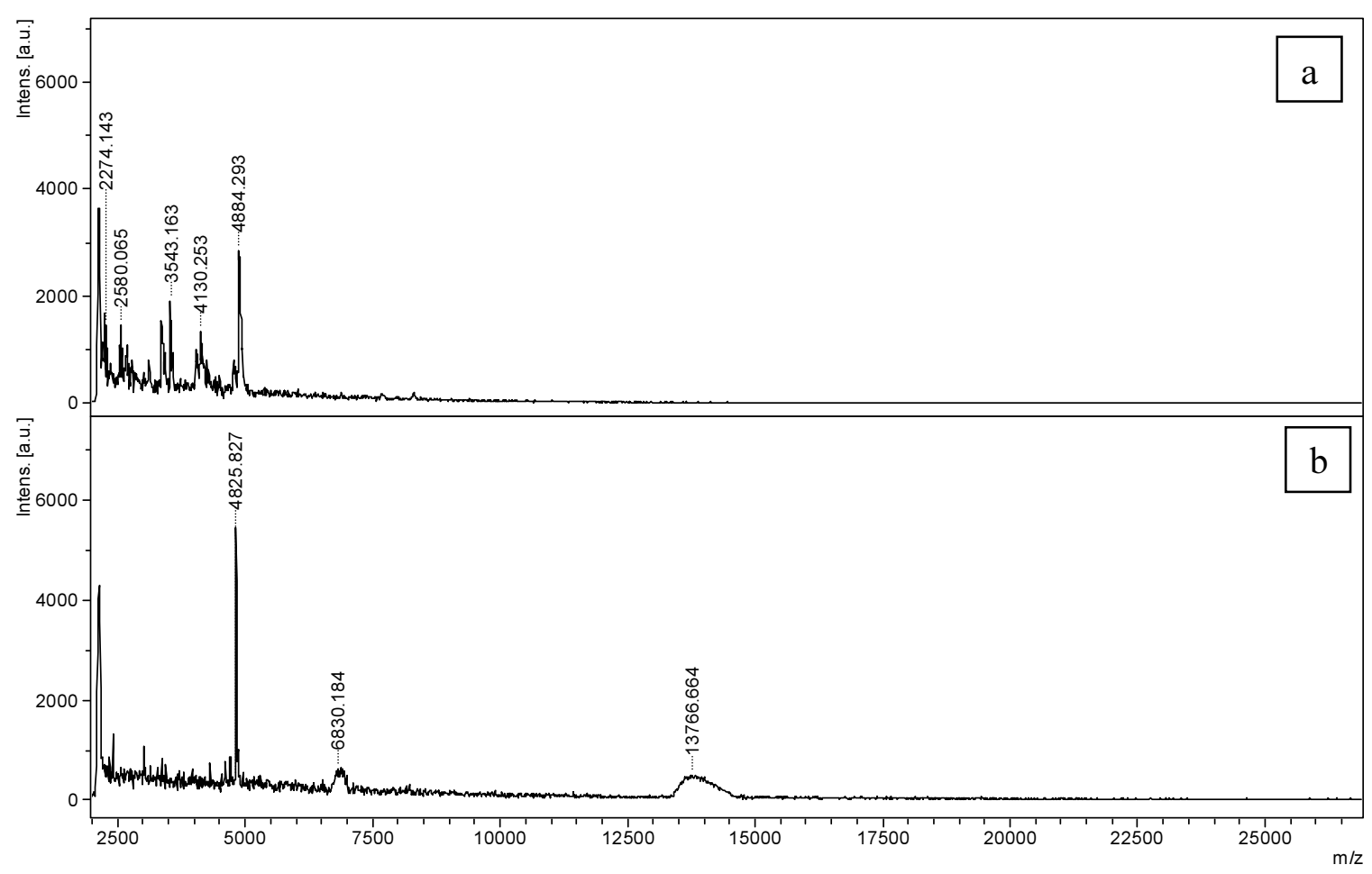

Fig. 3: Representative MALDI-TOF spectra of Bothrops alternatus and Bothrops pubescens Comparative MALDI-TOF mass spectra of $100 \mathrm{ng}$ of (a) Bothrops alternatus (b) Bothrops pubescens showing three outstanding peaks at around m/z 2274, m/z 3543, m/z 4884 and in Bothrops alternatus profile; three outstanding peaks at around m/z4825, m/z 6830 and $13766 \mathrm{inBothropspubescensprofile.}$ The products were detected as $[\mathrm{M}+\mathrm{Na}]+$ and/or $[\mathrm{M}+\mathrm{K}]+$ ions 
Based on this complexity, for both clinical and scientific purposes, the identification of the species associated with a snake venom accident becomes a real challenge.

The venom antigen concentration in blood depends on several factors, including the snake species and is detected by different types of ELISA (O'Leary et al., 2006; Kulawickrama et al., 2010). Therefore, in all cases that use ELISA, we refer to venom antigenaemia or venom antigen levels instead of venom concentration because only the venom compounds that react with antivenoms are detected.

The results reported in the present work showed a sensitivity of $0.1 \mathrm{ng}$ of venom of the Bothrops genus, corresponding to a concentration of $100 \mathrm{ng} / \mathrm{mL}$, obtained by MALDI TOF analysis. In Uruguay, the venom antigenaemia values found for Bothrops genus were between 20 and $140 \mathrm{ng} / \mathrm{mL}$ (Morais et al., 2012). These results were similar to the venom antigenaemia found by Bucher et al. (1997) with Bothrops lanceolatus bites in Martinique, with values ranging from 6 to $80 \mathrm{ng} / \mathrm{mL}$ (Bucher et al., 1997).

In comparison, regarding other snakes of the Bothrops genus, França et al. (2003) studied the venom level antigens in patients bitten by Bothrops jararaca and found a mean value of venom antigenaemia of 224 $\mathrm{ng} / \mathrm{mL}$, although when they measured the venom level in patients, more than $60 \%$ had venom levels lower than $200 \mathrm{ng} / \mathrm{mL}$. Additionally, patients bitten by Bothrops atrox in Colombia were found to have a mean of 67 $\mathrm{ng} / \mathrm{mL}$ of serum venom antigens before antivenom treatment (Otero et al., 1996).

The high sensitivity and reproducibility achieved by mass spectrometry suggest that the technique is suitable to detect venom in patient serum samples. In some cases, it could be necessary to concentrate the venom present in blood to obtain adequate sensitivity in all patients, especially in mild envenomations. Clinical assays will be necessary to clarify this point.

\section{Conclusion}

MALDI TOF-MS analysis is a rapid and costeffective tool that should be further explored because it may contribute to the development of a snake venom database of samples from patients bitten by snakes, similar to the case of bacterial identification.

\section{Acknowledgement}

Venoms of BP and BA were kindly provided by Serpentarium of Institute of Hygiene, UDELAR, Montevideo, Uruguay.

\section{Funding Information}

This work was supported PEDECIBA-Química, Uruguay.

\section{Author's Contributions}

Victor Morais: Participated in the conception and design of the study, carried out part of the experimental work and assisted in drafting the manuscript.

Norma Suárez: Participated in the conception and design of the study, carried out part of the experimental work and assisted in drafting the manuscript.

\section{Ethics}

This article is original and contains unpublished material. The corresponding author confirms that all of the other authors have read and approved the manuscript and no ethical issues involved.

\section{References}

Bucher, B., D. Canonge, L. Thomas, B. Tyburn, A. V. Robbe and V. Choumet, et al., 1997. Clinical indicators of envenoming and serum levels of venom antigens in patients bitten by Bothrops lanceolatus in Martinique. Research Group on Snake Bites in Martinique. Transact. R. Soc. Trop. Med. Hyg., 91: 186-90. DOI: 10.1016/s0035-9203(97)90219-4

Calvete, J.J., 2011a. Proteomic tools against the neglected pathology of snake bite envenoming. Expert Rev. Proteomics, 8: 739-758.

Calvete, J.J., 2011b. Snake Venomics, Antivenomics and Venom Phenotyping: The Ménage à Trois of Proteomic Tools Aimed at Understanding the Biodiversity of Venoms. In: Toxins and Hemostasis: From Bench to Bedside, Kini, R., K. Clemetson, F. Markland, M. McLane and T. Morita (Eds.), Springer, Dordrecht, ISBN-10: 978-90-481-9295-3, pp: 45-72.

Calvete, J.J., P. Juárez and L. Sanz, 2007. Snake venomics. strategy and applications. J. Mass Spectrom., 42: 1405-1414.

Chapman, J.R., D. Mebs, J.C. Boulain, C.G. Factor, 2003. Identification of Snake Species by Toxin Mass Fingerprinting of Their Venoms. In: Mass Spectrometry of Proteins and Peptides, Methods in Molecular Biology ${ }^{\mathrm{TM}}$, Chapman, J.R. (Ed.), Humana Press, Totowa, NJ, ISBN-10: 978-0-89603-609-3, pp: 317-335.

Chippaux, J.P. and Goyffon, M., 1998. Venoms, antivenoms and immunotherapy. Toxicon, 36: 823-846. DOI: 10.1016/S0041-0101(97)00160-8

Demirev, P.A. and C. Fenselau, 2008. Mass spectrometry for rapid characterization of microorganisms. Ann. Rev. Analytical Chem., 1: 71-93.

Fenselau, C.C., 2013. Rapid characterization of microorganisms by mass spectrometry-what can be learned and how? J. Am. Soc. Mass Spectrom., 24: 1161-1166. 
França, F.O.S., K.C. Barbaro, H.W. Fan, J.L. Cardoso and I.S. Sano-Martins et al., 2003. Envenoming by Bothrops Jararaca in Brazil: Association between venom antigenaemia and severity at admission to hospital. Transact. R. Soc. Trop. Med. Hyg., 97: 312-317. DOI: 10.1016/s0035-9203(03)90158-1

Gay, C., L. Sanz, J.J. Calvete and D. Pla, 2015. Snake venomics and antivenomics of Bothrops diporus, a medically important Pitviper in Northeastern Argentina. Toxins, 8: 1-13. DOI: $10.3390 /$ toxins 8010009

Hrabák, J., E. Chudácková and R. Walková, 2013. Matrix-assisted laser desorption ionization-time of flight (Maldi-TOF) mass spectrometry for detection of antibiotic resistance mechanisms: from research to routine diagnosis. Clin. Microbiol. Rev., 26: 103-14.

Karimi, A. and A. Amanati, 2016. Matrix-assisted laser desorption/ionization time of flight mass spectrometry: A new guide to infectious disease. Arch. Pedia. Infect. Dis. DOI: $10.5812 /$ pedinfect.31816

Krishnamurthy, T., U. Rajamani, P.L. Ross, R. Jabbour and H. Nair et al., 2000. Mass Spectral Investigations on Microorganisms. Toxin Rev., 19: 95-117. DOI: 10.1081/TXR-100100316

Kulawickrama, S., M.A. O'Leary, W.C. Hodgson, S.G.A. Brown and T. Jacoby et al., 2010. Development of a sensitive enzyme immunoassay for measuring taipan venom in serum. Toxicon, 55: 1510-1518.

Laemmli, U.K., 1970. Cleavage of structural proteins during the assembly of the head of bacteriophage T4. Nature, 227: 680-685.

Liang, X. K. Zheng, M.G. Qian and D.M. Lubman, 1996. Determination of bacterial protein profiles by matrix-assisted laser desorption/ionization mass spectrometry with high-performance liquid chromatography. Rapid Communicat. Mass Spectrom., 10: 1219-1226.

Markland, F., 1998. Snake venoms and the hemostatic system. Toxicon, 36: 1749-1800.

Matsui, T., Y. Fujimura and K. Titani, 2000. Snake venom proteases affecting hemostasis and thrombosis. Biochim. Biophys. Acta, 1477: 146-156.

Morais, V., A. Negrín, M.N. Tortorella and H. Massaldi, 2012. Evolution of venom antigenaemia and antivenom concentration in patients bitten by snakes in Uruguay. Toxicon, 60: 990-994. DOI: 10.1016/j.toxicon.2012.07.001

Morais, V., 2018. Antivenom therapy: Efficacy of premedication for the prevention of adverse reactions. J. Venom. Anim. Toxins Incl. Trop. Dis.
Morais, V., M. Baraibar and S. Carreira, 2006. Intraspecific variation of Bothrops pubescens (Cope, 1869) venom in Uruguay (Serpentes: Viperidae). J. Venom. Anima. Toxins Incl. Trop. Dis., 12: 604-611.

Morais, V.M. and H. Massaldi, 2009. Snake antivenoms: Adverse reactions and production technology. J. Venom. Anim. Toxins Incl. Trop. Dis., 15: 2-18.

O'Leary, M.A., G.K. Isbister, J.J. Schneider, S.G.A. Brown and B.J. Currie, 2006. Enzyme immunoassays in brown snake (Pseudonaja spp.) envenoming: Detecting venom, antivenom and venom-antivenom complexes. Toxicon, 48: 4-11.

Otero, R., J.M. Gutiérrez, V. Núñez, A. Robles and R. Estrada et al., 1996. A randomized double-blind clinical trial of two antivenoms in patients bitten by Bothrops atrox in Colombia. Trans. R. Soc. Trop. Med. Hyg., 90: 696-700. PMID: 9015522

Otero-Patiño, R., J.L. Cardoso, H.G. Higashi, V. Nunez and A. Diaz et al., 1998. A randomized, blinded, comparative trial of one pepsin-digested and two whole IgG antivenoms for Bothrops snake bites in Uraba, Colombia. Am. J. Trop. Med. Hyg., 58: 183-189. DOI: 10.4269/ajtmh.1998.58.183

Pineda, F.J., J.S. Lin, C. Fenselau and P.A. Demirev, 2000. Testing the significance of microorganism identification by mass spectrometry and proteome database search. Anal. Chem., 72: 3739-3744. PMID: 10959957

Pranada, A.B., G. Schwarz and M. Kostrzewa, 2015. MALDI biotyping for microorganism identification in clinical microbiology. In: Advances in MALDI and Laser-Induced Soft Ionization Mass Spectrometry, Cramer, R. (Ed.), Springer, Cham, ISBN-10: 978-3-319-04818-5, pp: 197-225.

Qian, J., J.E. Cutler and R.B. Cole, 2008. MALDITOF mass signatures for differentiation of yeast species, strain grouping and monitoring of morphogenesis markers. Anal. Bioanal. Chem., 392: 439-449. DOI: 10.1007/s00216-008-2288-1

Theakston, R.D.G., D.A. Warrell and E. Griffiths, 2003. Report of a WHO workshop on the standardization and control of antivenoms. Toxicon, 41: 541-557.

WHO, 2010. WHO Guidelines for the Production, Control and Regulation of Snake Antivenom Immunoglobulins, Geneva: WHO Technical Report Series.

WHO, 2019. Snakebite envenoming: A strategy for prevention and control. https://apps.who.int/iris/bitstream/handle/10665/324 838/9789241515641-eng.pdf?ua=1 